\title{
A Busca pela Residência Médica em Acupuntura na EPM-Unifesp
}

\section{The Search for Medical Residency in Acupuncture at EPM-Unifesp}

João Roberto Bissoto ${ }^{I}$

Dante Marcello Claramonte Gallian ${ }^{I}$

\section{PALAVRAS-CHAVE}

- Acupuntura.

- Internato e Residência.

- Entrevista

- Humanidades.

- Humanização da Assistência.

\section{RESUMO}

Este estudo nasceu da observação do considerável aumento das práticas integrativas em saúde e sua inserção no Sistema Único de Saúde do Brasil por meio da Política Nacional de Práticas Integrativas e Complementares em Saúde (PNPIC) de 2006. Surge, então, o questionamento dos motivos que levaram a esse aumento. O presente estudo analisou os porquês da busca de médicos recém-formados pela especialização em acupuntura na Universidade Federal de São Paulo, programa de residência médica recente na profissão. Os autores optaram pela metodologia da História Oral de Vida, tendo em vista seu potencial humanizador ao lidar com relatos de colegas e ainda pela rememoração do que foi vivido pelo entrevistado. A análise dos dados foi feita segundo o método de imersão e cristalização, baseado na fenomenologia hermenêutica, por meio do qual surgiram temáticas comuns nas narrativas dos entrevistados, as quais puderam ser analisadas com apoio na literatura vigente. Com base nas narrativas colhidas e analisadas, observou-se que um grande influenciador dos médicos na escolha da acupuntura é o descontentamento com a prática do modelo biomédico, que separa o paciente de sua totalidade, compartimentando o ser em múltiplas especialidades, o que transforma o paciente em pedaços sem avaliar sua existência como pessoa e sua saúde como um todo. Todos os narradores afirmaram considerar a acupuntura uma prática mais humana de fazer saúde, o que satisfaz o anseio de tratar o paciente, não apenas suas partes ou seus sintomas isolados, sendo esse fator fundamental para compreendermos o crescimento dessas práticas. Uma análise mais profunda das narrativas permitiu observar que na história de vida desses jovens médicos existem vivências que possibilitaram que eles estivessem dispostos a desenvolver sua humanidade de forma mais intensa. Outra característica notória que surgiu nas narrativas foi o fato de nenhum dos entrevistados ter tido contato com a acupuntura durante a graduação em Medicina, o que demonstra a incipiente inserção dessa prática no meio acadêmico, mesmo em se tratando de uma especialidade médica reconhecida pelo Conselho Federal de Medicina desde a década de 1990. 


\section{KEY-WORDS}

- Acupuncture.

- Internship and Residency.

- Interview.

- Humanities.

- Humanization of Assistance.

\begin{abstract}
This study resulted from the observed considerable increase in integrative practices in health and their insertion in the Brazilian Unified Health System through the National Policy of Integrative and Complementary Practices in Health (PNPIC) of 2006. The question then arises of the reasons that led to this increase. The present study analyzed the reasons behind newly trained physicians seeking to specialize in Acupuncture at the Federal University of São Paulo, a recent medical residency program in the profession. The authors used an Oral History methodology due to its humanizing potential when dealing with accounts given by colleagues and to help interviewees recall their experiences. Data analysis was carried out using the Immersion and Crystallization method, based on hermeneutic phenomenology, through which common themes emerged in the narratives of the interviewees, which could then be analyzed based on the current literature. From the collected and analyzed narratives it is observed that dissatisfaction with the practice of the biomedical model is a major factor that influences the physicians' choice of Acupuncture. That model is seen to treat the patient as a being that is compartmentalized into multiple specialties, transforming the patient into pieces without really assessing their existence as a person and their health as a whole. All the interviewees stated that they consider Acupuncture a more humane health care practice, corresponding to their longing to treat the patient, not only their parts, or their isolated symptoms, which factor is fundamental to understanding the growth of these practices. A deeper analysis of the narratives allowed us to observe that in the life history of these young doctors there are experiences that have enabled them to be willing to develop their humanity more intensely. Another conspicuous feature that emerged in the narratives was the fact that none of the interviewees had any contact with Acupuncture during their undergraduate medical training, which demonstrates its incipient insertion in the academic environment, even though this practice has been recognized by the Federal Council of Medicine as a medical specialty since the 1990s.
\end{abstract}

Recebido em: 10/12/18

Aceito em: 30/12/18

\section{INTRODUÇÃO}

A inclusão da acupuntura no Sistema Único de Saúde (SUS) se deu por meio de pressões dos movimentos sociais ${ }^{1}$, evidenciando essa busca pelo diverso, inclusive oriunda dos pacientes. Esse dado nos faz refletir sobre a necessidade real de humanização da medicina ocidental, uma vez que tem sido mostrado que a crise no sistema mecanicista da saúde é fator fundamental para a procura por práticas integrativas ${ }^{2}$.

Gallian $^{3}$ nos alerta para uma realidade advinda do avanço tecnológico aplicado à saúde, um processo crescente de desumanização. A "humanização", que era foco de debates acadêmicos e objeto de pesquisa, é hoje um termo corriqueiro e preditor de qualidade de serviços quando usado em publicidade. Em consequência desse teor publicitário do termo, surgiram inúmeros cursos de treinamento profissional humanizador na tentativa de responder à demanda social. Porém, devido à falta de embasamento teórico-científico acerca do que essa característica significa e representa, essa resposta é pouco efetiva na mudança do fazer saúde ${ }^{4}$.
Para muitos, algo como olhar nos olhos, falar pausadamente e dar atenção aos anseios trazidos pelo paciente é, simplesmente, sinônimo de educação. Mas os autores desse projeto pensam diferente. Gallian e Reginato ${ }^{5}$ mostram a ineficiência desse pensamento do ensino técnico e da criação de um conjunto de "habilidades humanizadoras".

Em 2006, com a implementação da Política Nacional de Práticas Integrativas e Complementares no SUS (PNPIC), o governo federal assumiu o compromisso com a integralidade do atendimento em saúde 1 . Antes chamada de "medicina alternativa" e não integrada ao SUS, hoje, a acupuntura, como principal expoente dessa modalidade ${ }^{6}$, cresceu 567\% de 2007 a 2011 no Estado de São Paulo, segundo a Secretaria de Estado de Saúde 7 .

Se para Palmeira ${ }^{8}$ a crise do cientificismo era uma provável justificativa para o aumento na busca das práticas integrativas, vemos que a inclusão dessas práticas em protocolos de pesquisa quantitativa em busca da verificação de sua eficiência se dá de maneira concomitante e independente do aumento da clínica, até de forma paradoxal. 
Ioro et al. ${ }^{9}$ apontam três principais razões para a busca por especialização em acupuntura: aprimoramento profissional, ampliação dos horizontes e busca por uma visão integral da saúde dos pacientes.

Entretanto, poucos estudos analisam de forma mais profunda e ampla o tema dos fatores motivadores que levam médicos formados no modelo biomédico a buscarem especialização em práticas como a acupuntura. Um trabalho, sem dúvida, importante e inspirador neste sentido é o de Rocha et $a .^{2}{ }^{2}$, que aborda a trajetória de médicos que iniciaram sua carreira na acupuntura algumas décadas atrás, antes mesmo de ela ser reconhecida como especialidade médica pelo CFM. Nesse trabalho, os autores discutem a introdução da acupuntura no SUS através das trajetórias de vida de seus pioneiros. A utilização do método da História Oral de Vida mostrou a possibilidade de explorar com amplitude e profundidade de que forma as vivências e experiências pessoais subjetivas determinaram as escolhas e a construção das trajetórias. Inspirada nessa abordagem, esta pesquisa procurou explorar de forma mais específica a temática das motivações com base em narrativas pessoais produzidas por meio da abordagem da História Oral de Vida.

Neste trabalho, analisamos os motivos que levam os médicos a buscarem uma especialização nessa área ainda jovem no ambiente acadêmico, tendo como referência a característica de integralidade da atenção em saúde que essa técnica representa. Além disso, a análise da percepção desses médicos sobre o conceito de humanização em saúde e sua relação com a medicina chinesa será fundamental para avaliar se suas motivações são congruentes com o anseio popular em busca das práticas integrativas.

A escolha da metodologia de História Oral de Vida se dá aqui pelo seu potencial humanizador. Segundo Teixeira Coe1 ho ${ }^{10}$, humanizar seria expandir a esfera do ser. Assim, Gallian ${ }^{3}$ vê nas humanidades o principal instrumento humanizador na formação do profissional de saúde, sendo a História Oral um potente método para esse objetivo se partirmos da definição já citada, uma vez que esta nos permite vivenciar indiretamente a vida do outro, expandindo nossa esfera do ser.

\section{METODOLOGIA}

Nossa pesquisa foi realizada entre os anos de 2016 e 2017, com apoio da Fundação de Amparo à Pesquisa do Estado de São Paulo (Fapesp). Foram selecionados quatro colaboradores, que foram entrevistados após aceitarem o convite e assinarem o Termo de Consentimento Livre e Esclarecido (TCLE), segundo as exigências do Comitê de Ética e Pesquisa da Unifesp, aprovado de acordo com o processo $n^{\circ} 1138 / 2016$. Os nomes aqui apresentados são fictícios para garantir a privacidade dos colaboradores.

O método escolhido foi a História Oral de Vida, por condizer com os ideais deste trabalho, abordando-se a subjetividade por meio das narrativas dos médicos, o que permite efetuar uma análise qualitativa e trabalhar as condições de humanização em saúde, questão presente na formação profissional. $\mathrm{Na}$ perspectiva da História Oral de Vida, portanto, o trabalho foi construído com base nas narrativas dos colaboradores, sendo neste caso quatro médicos residentes do Setor de Medicina Chinesa-Acupuntura da EPM-Unifesp, com idades de 27 a 30 anos, de ambos os sexos, o que estabelece nossa colônia ${ }^{11}$ como os médicos que se especializam em acupuntura pela Unifesp. Esse método consiste em quatro etapas para validação da narrativa obtida: (a) gravação das entrevistas; (b) confecção do documento escrito: transcrição, textualização, transcriação; (c) conferência e validação do documento escrito; (d) análise e confecção do texto final.

A primeira etapa consiste em três partes, começando com o contato inicial (pré-entrevista), no qual se estabeleceram as relações e se registraram os principais temas, lugares e objetos relacionados à experiência de vida dos entrevistados, seguido da gravação da entrevista de fato e terminando com os contatos a serem mantidos.

Na segunda etapa, foi realizada primeiramente a transcrição literal das entrevistas. Na textualização, as transcrições foram trabalhadas para se adequarem à norma escrita. Ao fim, na transcriação, o texto foi recriado em sua plenitude, sofrendo interferência do pesquisador, mas seguindo o combinado com o colaborador na pré-entrevista, o que legitima a transcriação.

A terceira etapa compreendeu a autorização completa dos textos finais pelos colaboradores, segundo parâmetros estabelecidos na carta de cessão, legitimando a passagem do oral para o escrito.

Na quarta etapa, as narrativas e a bibliografia foram analisadas e interpretadas para servirem de base para a dissertação final.

$\mathrm{Na}$ análise qualitativa dos dados obtidos foi utilizado o método de interpretação qualitativa denominado imersão/ cristalização, baseado na fenomenologia hermenêutica ${ }^{12}$. Surgiram, assim, subtemas comuns que foram agrupados em grandes temas, ilustrados com trechos das narrativas obtidas e em seguida analisados juntamente com a bibliografia levantada. 


\section{RESULTADOS E DISCUSSÃO}

Definir os motivos que levam uma pessoa a fazer determinadas escolhas em sua vida é, com certeza, uma tarefa ousada. Muitas vezes, nem os próprios protagonistas têm total consciência dos porquês, de forma que nosso trabalho é ousado em seus objetivos. Diferentemente dos estudos realizados por Ioro et al. ${ }^{9} \mathrm{ou}$ por Rocha et al. ${ }^{2}$, este trabalho analisa as vivências, vontades e frustrações que muitas vezes não são plenamente conscientes por meio da História Oral de Vida, tendo como narradores os residentes de acupuntura da Unifesp, ou seja, pessoas formadas mais recentemente, o que nos traz uma noção de atualidade.

Delgado $^{13}$ trabalha a questão da memória, do tempo e da história, nos indicando o papel edificador de personalidade e até mesmo de reinventor de nós mesmos que o rememorar permite, além de possibilitar por meio da narrativa a inclusão de seu interlocutor, fazendo-o viajar pelos acontecimentos e incorporar as experiências do narrador.

As temáticas que emergiram das narrativas neste estudo foram: a vivência do diferente na infância; a aproximação da acupuntura; escolha da especialização; e a visão da acupuntura como humanizadora, que serão tratadas nos itens seguintes.

\section{A vivência do diferente na infância}

Ouvir e avaliar as histórias de vida de outras pessoas, com passados tão diferentes, e tentar de algum modo notar questões comuns em suas vivências não é tarefa simples nem rápida, mas com certeza o resultado é gratificante. Dos padrões que emergiram durante o processo de imersão e cristalização, esse primeiro foi possivelmente o mais surpreendente. É notável que, por mais diferentes que fossem as histórias, os quatro narradores se depararam de alguma forma com experiências fora de sua zona de conforto ainda na infância e adolescência e lidaram com isso de forma positiva.

Se partirmos da definição de humanização desenvolvida por Teixeira Coelho de que humanizar seria expandir a esfera do ser ${ }^{10}$, temos que parte fundamental do desenvolvimento de um profissional humanizado se dá pelo encontro e pela vivência do diferente, do diverso. Desse modo, podemos afirmar que esses quatro profissionais eram mais humanizados ou apresentavam uma visão mais humana não por sua formação acadêmica, mas por suas vivências pessoais.

Carlos, por exemplo, nasceu em cidade pequena e tranquila na Itália, onde conheceu um modelo de medicina em que o médico conhecia seus pacientes e sua família, aconselhava e se sentia responsável pelo bem-estar dos habitantes da região. Ainda na infância, ele viu seu mundo mudar drasticamente com a mudança de país. Saiu de sua cidade pequena no interior da Itália e foi morar numa capital no Sul do Brasil.
Minha história de vida começa numa pequena cidade da Itália que possui cerca de 3 mil habitantes, chamada Pernumia, onde nasci. Minha infância foi muito boa, a cidade era bem tranquila [...]. Já com mais ou menos 11 anos de idade, eu vim para o Brasil porque minha mãe passou em um concurso do Ministério dos Exteriores para cuidar de escolas italianas aqui, como representante da Secretaria de Educação, que organiza o ensino italiano fora da Itália. Viemos então para Curitiba.

Felipe teve uma formação religiosa rígida contra a qual se rebelou na adolescência e procurou outras experiências com a religiosidade. Durante sua busca rebelde por identificação pessoal e explicações sobre a vida, ele se deparou com experiências diversas que abriram caminho para um entendimento de mundo certamente diferente do imaginado até então.

Sempre tive muito contato com a religiosidade, durante minha infância toda eu queria ser padre, até a adolescência eu tinha essa vontade, mas quando eu tive um contato mais profundo, já quase no seminário, para virar seminarista, percebi que aquilo não me explicava o que eu buscava saber [...] De santinho que ia virar padre me tornei completamente rebelde, gótico, em oposição à realidade que me cercava. E então eu conheci outras religiões, orientais, celtas, os wicca, e comecei a me interessar pelo diferente. Então minha adolescência foi uma fase de contrastes, começando como uma continuação da infância e mantendo o desejo de continuar a vida como seminarista e padre, passando para o momento de ruptura, de descobrimento de minhas verdades como uma fase de rebeldia.

Já Paula passou grande parte da infância em grande proximidade com a natureza, paisagens e cachoeiras, além de viajar com frequência para outros estados, até mesmo para a cidade de São Paulo, onde, com certeza, se deparou com uma realidade a que não estava acostumada. Estudou em um colégio enorme, com milhares de alunos, o que lhe permitiu conviver com pessoas diferentes no ambiente escolar.

O Mato Grosso é rico em natureza, como a Chapada dos Guimarães, e passei boa parte dela visitando as cachoeiras e fazendo trilhas, sempre aproveitando ao máximo o que as paisagens tinham para oferecer. Estudei em um colégio enorme, que tinha uns 4 mil alunos; para dar ideia da dimensão, na quinta série minha sala era a $5^{\underline{a}}$ I, ou seja, havia no mínimo mais sete salas da quinta série. Gostava muito de estudar lá, vivenciar aquela imensidão de escola com incontáveis alunos. Minha família gostava de passar as férias em nossa casa de 
Minas Gerais, que acabou ficando uma casa de campo, onde íamos a família toda, até os primos. Já no final do ano, costumávamos passar o Natal e ano-novo em São Paulo, com a família do meu pai, que é daqui mesmo. Aproveitávamos e ímos para a praia, geralmente para Santos, porque a família da minha mãe é de lá.

Notamos, então, um padrão já durante a infância: os narradores vivenciaram o diferente e se permitiram ampliar suas vivências ${ }^{10}$. Isto nos sugere, como haviam escrito Gallian e Reginato $^{5}$, que a visão humanizada da saúde não advém de cursos técnicos ou práticos que ensinam "habilidades humanizadoras", mas, sim, da permissão de vivenciar e experimentar aquilo que foge do nosso conforto e da nossa realidade.

\section{A aproximação da acupuntura}

Como a acupuntura não está no currículo da graduação em Medicina, a maioria dos profissionais se forma sem nenhum conhecimento da área e sem nenhum contato com a prática e ciência de uma especialidade médica reconhecida como tal pelo CFM. Desse modo, a primeira vivência com a acupuntura costuma ser fora do ambiente acadêmico, geralmente com o tratamento de um conhecido ou de si próprio por indicação, como sugerem Iorio et al. ${ }^{9}$. As narrativas colhidas neste estudo mostram que essa realidade se mantém até hoje, mesmo entre os que buscam a residência médica em acupuntura na EPM-Unifesp.

Acontece que durante uma aula de inglês do ensino médio eu estava com uma dor de cabeça bem intensa, e uma colega me falou para apertar um ponto na minha mão, que eu sei ser um ponto de acupuntura, dizendo que iria melhorar e de fato melhorou. Na época eu não me importei muito com isso, mas acho que ali já comecei a aceitar outras formas de terapias. (Thiago)

Durante os três anos em que trabalhei em um serviço, conheci um médico de origem oriental que era acupunturista e ele foi conversando comigo sobre essa área da medicina que eu desconhecia. Eu achei interessante e comecei a estudar o assunto, fui atrás de artigos científicos e materiais de medicina chinesa, vendo como funciona, e fiquei bem interessado, principalmente para o tratamento da dor, que éo mais pesquisado, não sabia que tinha tantas outras aplicações. (Carlos)

Foi nessa época que entrei em contato com a acupuntura pela primeira vez. Meu pai, depois que se especializou, sempre tratava a mim e minha irmã seguindo os princípios da medicina chinesa. Ele não usava agulha porque tínhamos muito medo, mas ele fazia laser nos pontos de acupuntura ou às vezes usava moxa. Minha mãe, que é pediatra, também sempre gostou da medicina não alopática, usava muitos chás e alimentos para nos tratar. Então, minha experiência com saúde e doença na infância não era de hospital e tomar remédio, mas, sim, me alimentar direito e fazer laser ou moxa, e sempre melhorávamos. Essa vivência, com certeza, me influenciou a querer fazer acupuntura. (Paula)

Apesar de existir uma vontade institucional de inserir tais práticas nos sistemas de saúde pelo mundo, como a "Estratégia da OMS sobre Medicina Tradicional (MT) 2002-2005" e a Política Nacional de Práticas Integrativas e Complementares (PNPIC) de 2006 no Brasil ${ }^{14}$, essas falas mostram que as práticas complementares de saúde, em especial a acupuntura, ainda não estão inseridas na formação médica geral, mesmo entre os profissionais que as escolhem como área de especialização. Iorio et al. ${ }^{9}$ comentam o crescimento acadêmico que a acupuntura teve nos últimos anos, mas também mostram que a relação entre a graduação e esse meio acadêmico ainda se mostra incipiente. Paula deixa claro esse ponto em sua narrativa:

Na faculdade não tive contato nenhum com medicinas integrativas na grade. Minha madrinha é acupunturista, então o contato que eu tive foi passar um tempo no consultório dela. Mas no curso mesmo, nem citavam. Uma turma anterior a minha tentou fundar uma liga acadêmica de acupuntura, mas teve dificuldade de achar preceptor e organizar o espaço, professores; acabou que o projeto não deu certo. Como eu sempre tive contato com a prática da medicina chinesa, a graduação foi muito frustrante para mim.

Rocha et al. ${ }^{2}$ corroboraram esse achado mostrando que a aproximação da acupuntura por seus narradores se deu após uma desilusão com a prática médica ocidental e não por um interesse na área durante a graduação.

Esses dados nos mostram o quão necessária se faz a introdução de práticas complementares ainda na graduação. Desde 2006, com a implantação da Política Nacional de Práticas Integrativas e Complementares no SUS (PNPIC) e tendo a acupuntura como principal representante dessa categoria ${ }^{6}$, temos necessidade de trazer outras práticas de fazer saúde para os centros acadêmicos, seja como estratégia de humanização, expandindo a vivência dos alunos, seja como conhecimento geral cada vez mais necessário ao futuro profissional, tendo em vista o crescimento da procura por atendimentos nessa especialidade - de 567\% de 2007 a 2011 no Estado de São Paulo, segundo a Secretaria de Estado de Saúde . 


\section{Escolha da especialização}

Rocha et al. ${ }^{2}$ abordaram em seu trabalho a introdução da acupuntura e a busca dos profissionais por esse método, encontrando como principal motivo para isto a crise do sistema de saúde baseado no modelo mecanicista biomédico.

De forma semelhante, Iorio et al. ${ }^{9}$ reuniram os motivos da procura pela especialização em acupuntura em três grandes grupos: "aprimoramento profissional”, "ampliar seu próprio horizonte de vida" e "compreender o paciente numa dimensão mais abrangente". Esse trabalho também indicou que "ampliar seu próprio horizonte de vida" foi respondido por $56,9 \%$ dos entrevistados, o que sugere que os médicos estão em busca de uma experiência humanizadora.

As narrativas colhidas e analisadas em nossa pesquisa corroboram os trabalhos anteriores, mostrando que a escolha da especialização em acupuntura se relaciona com uma insatisfação referente à prática da medicina ocidental e com a busca de uma prática mais abrangente e mais humana.

No Provab, quando você vai para a Saúde da Família, você vê o universo real da coisa. Sendo cirurgião, eu não teria ajudado ninguém ali. A maioria dos fatores eram sociais, muitas vezes emocionais e eu não ia conseguir ajudar ninguém. Foi um choque de realidade que me abalou muito. (Felipe)

Para mim, acredito que a abordagem da medicina chinesa é muito mais completa, mais ampla, mais humana. Ela analisa e leva em consideração aspectos que são muitas vezes desconhecidos ou até mesmo desconsiderados pela medicina ocidental. Ela trabalha a questão da emoção, que é tão vigente, tão forte, tão pungente, na nossa vida e que achamos não ser parte da medicina ou que não deve ser abordada pelo médico, a não ser que seja psiquiatra. E além disso, ela trabalha com um conceito que considero fundamental, que é o conceito de autocura, que através de estímulos adequados geramos a condição da própria cura. E isso vai de encontro ao conceito de doença. (Thiago)

Leite e Strong ${ }^{15}$ nos mostram que o cuidar da vida não pode estar desvinculado de compreender o outro em sua totalidade e em sua pluralidade, sendo essa visão mais abrangente uma característica fortemente presente nas práticas integrativas de modo geral e na acupuntura especificamente. Esse fator está presente nas narrativas como ponto de decisão pela especialidade e como fonte de satisfação com essa decisão.

Por isso vim para cá e, aparentemente, está me respondendo todas aquelas perguntas que as outras áreas não me respon- diam, além de me apresentar uma visão de saúde diferente, que aborda os aspectos energéticos, mais subjetivos, levando sempre em consideração o humano doente e não apenas as doenças. Eu sempre tive muita dificuldade em colocar os fatos da vida e sintomas em caixinhas para rotular um paciente, afinal somos todos humanos. (Felipe)

Como eu sempre tive contato com a prática da medicina chinesa, a graduação foi muito frustrante para mim. A medicina que aprendemos na faculdade é muito setorizada e compreende apenas um sistema de queixa-conduta. Por exemplo, se o paciente apresentava problema de pele, encaminhávamos para a dermatologia, se o problema era de digestão, para a gastroenterologia. Mas para mim eu via em muitos casos a relação das doenças pela ótica da medicina chinesa, porque uma desarmonia pode afetar vários órgãos. Acontece que isso não era bem-visto pelos professores e colegas, como se fosse outra medicina, sem comunicação com o que eles faziam. (Paula)

Diferentemente do trabalhado por Rocha et al. ${ }^{2}$ e por Iorio et al. ${ }^{9}$, as narrativas aqui analisadas mostram que os médicos procuraram a acupuntura como primeira especialização por meio do programa de residência médica em acupuntura da EPM-Unifesp, ou seja, são profissionais mais jovens que os analisados nos outros trabalhos. Esse dado pode ser parcialmente explicado pelo aumento dos serviços de saúde que oferecem a acupuntura como prática, facilitando o contato com a técnica, mas, ao mesmo tempo, demonstra uma insatisfação com a medicina ocidental tradicional logo no início da carreira, diferentemente do mostrado nas outras pesquisas. Como sugere $\mathrm{Cruz}^{16}$, o modelo biomédico e tecnicista avançou muito no estudo e investigação das doenças em detrimento do cuidar dos sujeitos doentes, e as narrativas desse trabalho apontam exatamente o descontentamento dos profissionais recém-formados com essa realidade, em que a medicina se tornou uma ciência das doenças e abandonou em parte as pessoas por trás delas.

\section{Visão da acupuntura como humanizadora}

No trabalho de Iorio et al. ${ }^{9}, 88,4 \%$ dos entrevistados responderam que acreditam que a relação médico-paciente na acupuntura é diferente daquela da medicina ocidental. É notável que a busca da especialização em acupuntura está ligada a uma insatisfação das relações profissionais, como sugere esse mesmo trabalho ao descrever que $65 \%$ dos entrevistados responderam estar insatisfeitos ou pouco satisfeitos com a especialidade que exerciam na medicina convencional. Em nossa pesquisa encontramos algo semelhante: 
Medicina chinesa tem uma visão bem diferente do processo saúde-doença e da relação médico-paciente. Por exemplo, muitas queixas que os pacientes trazem na consulta de um médico tradicional são ignoradas por não se encaixarem em uma fisiopatologia específica, por se considerar uma queixa comum, autolimitada e sem importância. Aí o médico tradicional acaba tratando da doença e não do paciente. Já na acupuntura, a visão é mais ampla, e cada queixa que o paciente traz é interpretada dentro da teoria de uma desarmonia energética, e isso influi no diagnóstico e no tratamento que o paciente vai receber. (Carlos)

Hoje acredito que a medicina chinesa se presta a olhar o paciente por outros lados, levando em consideração todas as diferenças que existem entre cada um, a família, o meio social, a educação que a pessoa tem, os hábitos, tudo isso pode interferir na saúde. Acho que a humanização é você compreender e trabalhar com isso, procurando trazer consciência para o paciente, porque eu acho que a palavra do processo de cura é consciência. Precisa trazer consciência para o paciente do que está gerando aquilo que não está legal para ele. (Thiago)

Diferentemente do trabalho de Iorio et al. ${ }^{9}$, por conta do método escolhido, nosso trabalho permitiu compreender as vivências dos narradores em sua prática profissional e os descontentamentos que os levaram a buscar uma prática que, na visão deles, se mostrou mais humanizada. Felipe, por exemplo, ao participar do programa do governo Provab, se deparou com uma realidade da qual não estava consciente e notou o quanto uma medicina mais geral, que dê mais atenção ao fator social e subjetivo dos doentes, fazia falta em sua prática de saúde. Paula demonstrou insatisfação com a prática ocidental por esta não considerar a maioria das queixas que os pacientes traziam para a consulta, o que a fazia se sentir tratando apenas de uma doença desconectada do doente.

Eu via aquela prática do modelo ocidental como uma medicina sintomática, uma espécie de "cale a boca" do doente. Se durante uma consulta o paciente se queixava de azia, dava omeprazol, se fosse cefaleia, dava dipirona. Quase nunca abordávamos a causa dos problemas, o que torna uma prática pouco eficiente, na minha visão, porque só gera uma coisa cada vez mais comum, que é a polifarmácia, com um somatório de efeitos adversos das medicações. (Paula)

Esses questionamentos pessoais que surgem durante as narrativas trazem um componente humano fundamental para o objetivo do trabalho, que não só investiga o que leva um mé- dico a fazer residência em acupuntura na EPM-Unifesp, mas também analisa a visão da humanização em saúde.

Segundo a definição de Faiman et al. ${ }^{17}$, humanização:

É o processo de transformação da cultura institucional que reconhece e valoriza os aspectos subjetivos, históricos e socioculturais dos pacientes e profissionais, melhorando as condições de trabalho e a qualidade do atendimento, por meio da promoção de ações que, à competência técnica e tecnológica, agregam o valor da dimensão subjetiva dos participantes.

Se aplicarmos essa definição, entenderemos que a acupuntura apresenta uma visão e uma prática mais voltadas ou mais atentas aos aspectos da vivência dos pacientes e até mesmo da interpretação que eles dão às condições de saúde e doença que apresentam, sendo esse um motivo que traz nas narrativas a certeza dos narradores de que praticam uma medicina mais humanizada e abrangente.

\begin{abstract}
A medicina chinesa é mais humana por abordar toda a complexidade do paciente, queixas físicas e emocionais; até a vida intrauterina é questionada, porque buscamos entender quem é aquela pessoa que adoeceu. A doença pode ser a mesma, mas o doente é único, não tem receita de bolo para tratar uma população inteira, porque a vivência pessoal é única e interfere no diagnóstico, bem como no tratamento. (Paula)
\end{abstract}

\section{CONSIDERAÇÕES FINAIS}

Nosso trabalho mostrou que a escolha profissional de uma especialização em práticas integrativas tem suas raízes na infância, quando o futuro profissional se permite abrir para experiências diversas, saindo de sua zona de conforto e se tornando, por isso, mais humano. Assim, esse jovem, quando se depara com uma medicina mecanicista e segmentada como a ensinada nas universidades brasileiras, se decepciona já durante a graduação. Diferentemente do que mostraram trabalhos anteriores, que apontaram um descontentamento profissional que se deu ao longo da carreira, aqui vemos que os colaboradores já se mostravam insatisfeitos com a prática médica antes mesmo de se formarem, por não se adequarem ao modelo de prática protocolar e segmentado que chamamos de modelo biomédico.

Mesmo encontrando na literatura e em decisões institucionais, como na Organização Mundial de Saúde, uma defesa das práticas integrativas como fator de influência importante para a manutenção da saúde, observamos neste trabalho que os colaboradores, todos formados nos últimos cinco anos, criticaram a total ausência dessas medicinas integrativas nas res- 
pectivas graduações e até mesmo a existência de uma crítica debochada por parte do meio acadêmico. Isto nos indica ser ainda muito incipiente a vivência das práticas integrativas nos ambientes universitários, uma vez que, mesmo entre os profissionais que buscam especialização nessa área como primeira opção de carreira, nenhum deles teve contato com a acupuntura no ambiente acadêmico.

As narrativas coletadas são claras ainda em sua crítica ao modelo biomédico e cientificista do fazer saúde hoje ensinado nas universidades. A segmentação do ser humano em subespecialidades prejudica a relação médico-paciente e o processo de entendimento e tratamento de uma enfermidade apresentada pelo paciente, segundo nossos colaboradores. Para eles, a acupuntura se mostra uma prática mais integral e humana, que amplia os conhecimentos do adoecimento e propicia ao doente participar do seu tratamento de forma ativa, buscando equilibrar os fatores geradores de saúde e doença. Essa característica da acupuntura pesou na escolha profissional dos narradores, que priorizam uma medicina mais abrangente e mais humanizada.

O caráter subjetivo da análise dos colaboradores enriqueceu a discussão do tema, o que demonstra ter sido a História Oral a metodologia adequada aos objetivos desta pesquisa, possibilitando a vivência das experiências do outro por meio de sua narrativa, o que trabalha em nós o potencial humanizador desse trabalho.

\section{REFERÊNCIAS BIBLIOGRÁFICAS}

1. Brasil. Ministério da Saúde do Brasil. Política nacional de práticas integrativas e complementares no SUS - PNPIC-SUS: atitude de ampliação de acesso. Brasília: Ministério da Saúde, 2006. (Série B. Textos Básicos de Saúde)

2. Rocha, SP; Gallian, DMC; Benedetto, MAC; Fernandez, FHB. Acupuntura no Sistema Único de Saúde no município do São Paulo: História Oral e Memória. Ciência e Saúde Coletiva, 20(1):155-164. Rio de Janeiro, Jan. 2015.

3. Gallian, DMC. A (re)humanização da medicina. Psiquiatria na Prática Médica [online], Vol. 33, n. 2, abr.-jun 2000, pp. 5-8. [capturado em 16 Jun, 2015] Disponível em: http:// www2.unifesp.br/dpsiq/polbr/ppm/especial02a.html.

4. Gallian, DMC; Ponde, LF; Ruiz, R. Humanização, Humanismos e Humanidades: Problematizando conceitos e práticas no contexto da saúde no Brasil. Revista Internacional de Humanidades Médicas, [online] v1, n1, 2012. [capturado em 16 Jun, 2015]. Disponível em: http://www2. unifesp.br/centros/cehfi/documentos/Volumen1_Numero1_2012_Revista_Internacional_de_Humanidades_ Medicas.pdf.
5. Gallian, DMC; Reginato, V. Relação assistencial e sua humanização. In: Ramos, DLP (org.): Bioética, Pessoa e Vida, 1 ed, 2009. São Caetano do Sul, Difusão Editora, pp. 117-133.

6. Lie, D. Conference Report: 2nd International Scientific Conference on Complementary, Alternative and Integrative Medicine Research. April 12-14, 2002, Boston, Massachusetts.

7. Brasil. Portal de notícias. Aumentam aplicações de acupuntura pelo SUS de São Paulo. Portal Brasil. [online] 2013. [capturado em 09 Abr, 2015] Disponível em: http:/ /www. brasil.gov.br/noticias/arquivos/2013/01/10/aumenta-as-aplicacoes-de-acupuntura-pelo-sus-de-sao-paulo.

8. Palmeira, G. A acupuntura no ocidente. Caderno de Saúde Pública [online]. Rio de Janeiro, v. 6, n. 2, 1990. [capturado em 25 Mai, 2015] Disponível em: http://www.scielo.br/ scielo.php

9. Iorio, RC; Siqueira, AAF; Yamamura, Y. Acupuntura: motivações de médicos para a procura de especialização. RevBrasEducMéd [online]. 2010, vol.34, n.2, pp. 247-254. [capturado em 16 Jun, 2015]. Disponível em: http:/ / www. scielo.br/pdf/rbem/v34n2/a08v34n2.pdf.

10. Coelho, T. A Cultura como Experiência. In: Ribeiro, RJ (org.) Humanidades; um novo curso na USP. São Paulo, Edusp, 2001.

11. Meihy, JCSB. Manual de história oral. São Paulo: Loyola, 2005.

12. Borkan, J. Immersion/Cristalization in: Miller WC, Crabtree BF. Doing Qualitative Research. USA: Sage Publications; 1999.

13. Delgado, LAN. História oral e narrativa: tempo, memória e identidades. História Oral, 6, 2003, p. 9-25.

14. Barros, NF; Siegel, P; Simoni, C. Política Nacional de Práticas Integrativas e Complementares no SUS: passos para o pluralismo na saúde. Cad. Saúde Pública [online]. 2007, vol.23, n.12, pp.3066-3067. [capturado em 16 Jun, 2015] Disponível em: http:/ /www.scielo.br/scielo.php?pid=s0102$-311 \times 2007001200030 \&$ script $=$ sci_arttext.

15. Leite, TAAF; Strong, MI. A influência da visão holística no processo de humanização hospitalar. Mundo Saúde, São Paulo. 2006: abr/jun 30 (2): 203-214.

16. Cruz, J. A relação médico-paciente em algumas obras literárias. Revista da Associação Medica Brasileira 2012; 58(3):272-275.

17. Faiman, CS; Danesi, D; Rios, IS; Zaher, VL. Os cuidadores: A prática clínica dos profissionais de saúde. Mundo Saúde. $2003 ; 27: 254-257$. 


\section{CONTRIBUIÇÃO DOS AUTORES}

Coube a João Bissoto o trabalho de coleta das narrativas, bem como a execução do texto final, e a Dante Gallian coube a orientação metodológica e a revisão do trabalho final.

\section{CONFLITO DE INTERESSES}

Os autores declaram não haver conflito de interesses na execução desse trabalho.

\section{ENDEREÇO PARA CORRESPONDÊNCIA}

Rua Loefgreen, 2032, Vila Clementino, São Paulo, SP-Brasil. CEP 04040-031 